\title{
Comparative effectiveness of a fixed-dose combination of losartan + HCTZ versus bisoprolol + HCTZ in patients with moderate- to-severe hypertension: results of the 6-month ELIZA trial
}

This article was published in the following Dove Press journal:

Vascular Health and Risk Management

26 September 2013

Number of times this article has been viewed

\section{GD Radchenko \\ YM Sirenko \\ SM Kushnir \\ OO Torbas \\ AS Dobrokhod}

Secondary Hypertension Department, National Scientific Center, Strazhesko Institute of Cardiology, Kiev, Ukraine
Correspondence: GD Radchenko Department of Secondary Hypertension, National Scientific Center, Strazhesko Institute of Cardiology, 5 Narodnogo Opolchenia Str, 03680 Kiev, Ukraine Email rganna@bigmir.net
Background: The aim of this study was to compare the antihypertensive efficacy of losartan $100 \mathrm{mg}+$ hydrochlorothiazide (HCTZ) $25 \mathrm{mg}$ versus bisoprolol $10 \mathrm{mg}+$ HCTZ $25 \mathrm{mg}$ and their influence on arterial stiffness and central blood pressure (BP).

Methods: Of 60 patients with a mean BP of $173.3 \pm 1.7 / 98.4 \pm 1.2 \mathrm{mmHg}, 59$ were randomized to losartan + HCTZ $(n=32)$ or bisoprolol + HCTZ $(n=27)$. Amlodipine was added if target BP was not achieved at 1 month, and doxazosin was added if target BP was not achieved after 3 months. Body mass index, office and 24-hour ambulatory BP, pulse wave velocity (carotid-femoral [PWVE] and radial [PWVM]), noninvasive central systolic BP, augmentation index (AIx), laboratory investigations, and electrocardiography were done at baseline and after 6 months of treatment.

Results: Losartan + HCTZ was as effective as bisoprolol + HCTZ, with target office BP achieved in $96.9 \%$ and $92.6 \%$ of patients and target 24 -hour BP in $75 \%$ and $66.7 \%$ of patients, respectively, after 6 months. Effective treatment of BP led to significant lowering of central systolic BP, but this was decreased to a significantly $(P<0.05)$ greater extent by losartan + HCTZ $(-23.0 \pm 2.3 \mathrm{mmHg})$ than by bisoprolol $+\mathrm{HCTZ}(-15.4 \pm 2.9 \mathrm{mmHg})$ despite equal lowering of brachial BP. Factors correlated with central systolic BP and its lowering differed between the treatment groups. Losartan $+\mathrm{HCTZ}$ did not alter arterial stiffness patterns significantly, but bisoprolol + HCTZ significantly increased AIx. We noted differences in $\triangle \mathrm{PWVE}, \triangle \mathrm{PWVM}$, and $\triangle \mathrm{AIx}$ between the groups in favor of losartan $+\mathrm{HCTZ}$. Decreased heart rate was associated with higher central systolic BP and AIx in the bisoprolol + HCTZ group, but was not associated with increased AIx in the losartan + HCTZ group.

Conclusion: Although both treatments decreased both office and 24-hour BP, losartan + HCTZ significantly decreased central systolic BP and had a more positive influence on pulse wave velocity, with a less negative effect of decreased heart rate on AIx and central systolic BP.

Keywords: arterial hypertension, combination therapy, central blood pressure, arterial stiffness

\section{Introduction}

In light of the latest recommendations concerning blood pressure $(\mathrm{BP}) \geq 160 / 100 \mathrm{mmHg}$, patients with hypertension should be initially treated with combined antihypertensive therapy. ${ }^{1}$ This approach has certain advantages: about two-thirds of patients can achieve target BP; time taken to reach BP control is reduced; components of the 
combination have a synergistic effect in terms of BP lowering and duration of effect; there is less likelihood of adverse effects because of the lower doses used and offsetting of the adverse effects of one drug component by another; and adherence with treatment is increased, especially with fixeddose combinations. Consequently, pharmaceutical companies are increasingly manufacturing fixed-dose combinations of antihypertensive drugs.

One of the most promising combinations consists of an angiotensin receptor blocker and a diuretic, ${ }^{2,3}$ and the efficacy of angiotensin receptor blockers has been demonstrated in many clinical trials. In the LIFE (Losartan Intervention For Endpoint reduction in hypertension) trial, long-term combination therapy with losartan + hydrochlorothiazide (HCTZ) was associated with a significant reduction in cardiovascular events (stroke, cardiovascular mortality, new diagnosed diabetes, paroxysmal atrial fibrillation) compared with atenolol + HCTZ in patients with hypertension and electrocardiographic signs of left ventricular hypertrophy. ${ }^{4}$ However, reduction in office BP was the same in both groups. The positive influence of losartan was explained by a more significant reduction in electrocardiographic and echocardiographic signs of left ventricular hypertrophy, which decreased rates of paroxysmal atrial fibrillation, decreased carotid artery wall thickness, improved the elastic properties of arterial walls, decreased hypertrophy in resistance vessels, improved endothelial function, inhibited platelet aggregation, and decreased serum uric acid levels.

It has recently been reported that long-term treatment with $\beta$-blockers, particularly in combination with a thiazide diuretic, increases the risk of diabetes, ${ }^{1}$ and there is some evidence of $\beta$-blockers being less effective in the prevention of cardiovascular events. ${ }^{5,6}$ Some national recommendations have excluded $\beta$-blockers from the first-line antihypertensive agents, ${ }^{6}$ but they are frequently used in patients with coronary heart disease and heart failure. In the 2007 European Society of Hypertension and European Society of Cardiology guidelines, $\beta$-blockers are still considered first-line drugs for the treatment of hypertension, particularly in patients with coronary heart disease, heart failure, or arrhythmias. ${ }^{1,7}$ It seems irrational to exclude $\beta$-blockers but to retain diuretics in this context, given that both classes of drugs have been shown to have a negative effect on glucose metabolism. ${ }^{8}$ Further, certain trials and meta-analyses have shown that $\beta$-blockers are no less effective than other antihypertensive drugs and that they are more effective in patients with coronary heart disease. In diabetes trials, $\beta$-blockers were shown to decrease BP and this alone led to a lower complication rate..$^{1,9,10,11}$ The $\beta$-blockers have been retained in the 2007 European guidelines for the treatment of diabetes, ${ }^{11}$ but highly $\beta_{1}$-selective agents and those with a vasodilatory action are preferred.

We compared the effects of losartan + HCTZ and bisoprolol + HCTZ on office BP, 24-hour BP, central systolic BP, and arterial stiffness in patients with moderate-to-severe arterial hypertension in a study known as ELIZA (Effectiveness and safety of Losartan $100 \mathrm{mg}+$ hydrochlorothIaZide $25 \mathrm{mg}$ versus bisoprolol $10 \mathrm{mg}$ + hydrochlorothiazide $25 \mathrm{mg}$ treatment in patients with moderate-to-severe Arterial hypertension). The main features of this trial included high starting doses for all 3 drugs, long-term treatment with 6 months of follow-up, an aggressive approach, with addition of other antihypertensive drugs until achievement of target BP, and use of several methods to assess antihypertensive efficacy.

Choice of antihypertensive therapy was based on several considerations. First, the LIFE trial had shown a more favorable effect of losartan than atenolol on rates of study endpoints and an equal effect on brachial BP, but possible differences in central BP were not investigated. The Strong Heart Study demonstrated a more prominent role of central BP than brachial BP in cardiovascular complications. ${ }^{12,13}$ ASCOT (the Anglo-Scandinavian Cardiac Outcomes Trial) showed differences between antihypertensive drugs in their ability to lower central BP but no difference in their ability to lower brachial BP, that may lead to differences in their ability to prevent cardiovascular disease. ${ }^{14}$ Second, critics of the LIFE trial suggested that the comparison was inappropriate because atenolol is arguably the poorest of all the $\beta$-blockers. ${ }^{5,6}$ Therefore, in our trial, losartan was compared with the highly selective agent, bisoprolol. , $^{5,10,11,15-18}$ Bisoprolol is the only $\beta$-blocker approved by the US Food and Drug Administration as a fixed-dose combination with HCTZ $6.25 \mathrm{mg}$ for patients with hypertension and is one of the drugs (along with metoprolol, carvedilol, and nebivolol) recommended for the treatment of heart failure. ${ }^{19}$ Third, the meta-analysis by Ong et al demonstrated that all the antihypertensive drug classes had an equal effect on arterial stiffness, but angiotensin receptor blockers were not included in their analysis because of lack of results from the relevant trials. $^{20,21}$ Therefore, we studied the effect of losartan, an angiotensin receptor blocker, on arterial stiffness.

\section{Materials and methods \\ Patients}

Sixty patients with moderate-to-severe hypertension (mean BP $173.3 \pm 1.7 / 98.4 \pm 1.2 \mathrm{mmHg}$ ) were recruited. One patient was excluded for nonattendance at the second and 
third monthly office visits. Inclusion criteria were: aged 18-75 years; essential arterial hypertension; office systolic $\mathrm{BP}$ at randomization $\geq 160 \mathrm{mmHg}$ and $<220 \mathrm{mmHg}$ and diastolic $\mathrm{BP} \geq 90 \mathrm{mmHg}$ and $<120 \mathrm{mmHg}$. All patients signed an informed consent form and the study was approved by the local ethics committee.

Exclusion criteria were a positive history of angioedema, hyperkalemia $(>5.5 \mathrm{mmol} / \mathrm{L})$ or hypokalemia $(<3.5 \mathrm{mmol} / \mathrm{L})$, bilateral renal artery stenosis, acute heart failure, cardiac arrhythmias (chronic atrial fibrillation, frequent premature ventricular and atrial contractions, ventricular or supraventricular tachycardia, tachycardia [heart rate $>100$ beats per minute]), atrioventricular block, sinus bradycardia, sick sinus syndrome, valvular disease, pregnancy or lactation, malignant hypertension, episodes of marked arterial hypotension (systolic $\mathrm{BP}<90 \mathrm{mmHg}$ ), bronchial asthma, decompensated liver disease (at least a three-fold elevation in serum aspartate transaminase and/or alanine transaminase), acute or chronic renal failure (serum creatinine $>133 \mu \mathrm{mol} / \mathrm{L}$ ), New York Heart Association class II or higher heart failure, history of myocardial infarction or acute cerebrovascular events, stable angina (functional grade 3-4) or vasospastic angina, cancer, infectious disease, conditions associated with endogenous depression (or depressive conditions in family members), diabetes mellitus, body mass index $\geq 35 \mathrm{~kg} / \mathrm{m}^{2}$, advanced peripheral arterial disease, Raynaud's syndrome, postsurgical conditions (surgery within 1 month prior to inclusion), administration of steroidal or nonsteroidal anti-inflammatory drugs, contraceptives, pronounced psychiatric disorders, withdrawal of prior therapy not feasible, and participation in another trial.

Almost equal numbers of men and women with newly diagnosed hypertension were included, and the majority were overweight (Table 1). Those who had been treated for hypertension previously had most often received angiotensin-converting enzyme inhibitors, and $37.3 \%$ of patients had relatives aged $<55$ years who suffered from cardiovascular disease. The majority had a carotid-femoral pulse wave velocity (PWVE) $>12 \mathrm{~m} / \mathrm{sec}$ and their mean central systolic BP was lower than their office systolic BP, which is quite normal, (the greater the distance from the aorta to the peripheral arteries, the earlier direct and reflected pulse waves meet, and the greater the systolic BP is accordingly) ${ }^{22-24}$ The difference may be as high as $20 \mathrm{mmHg},{ }^{21-24}$ and this was confirmed in our study.

The following parameters were measured in all patients at baseline and during treatment: height and body weight, office systolic BP, diastolic BP, heart rate, ambulatory blood
Table I Clinical and demographic characteristics of all study patients (mean \pm standard deviation, $\mathrm{n}, \%$ )

\begin{tabular}{ll}
\hline Characteristic & $\mathbf{n}=\mathbf{5 9}$ \\
\hline Women/men, $\mathrm{n}(\%)$ & $25(42.4) / 34(50)$ \\
Age, years & $53.8 \pm 2.4$ \\
Baseline systolic BP, $\mathrm{mmHg}$ & $173.3 \pm 1.7$ \\
Baseline diastolic BP, $\mathrm{mmHg}$ & $98.4 \pm 1.2$ \\
$\mathrm{HR}$, beats per minute & $71.0 \pm 2.0$ \\
$\mathrm{BMI}, \mathrm{kg} / \mathrm{m}^{2}$ & $30.0 \pm 1.4$ \\
New diagnosed AH, $\mathrm{n}(\%)$ & $34(57.6)$ \\
Previous ACE inhibitor therapy, $\mathrm{n}(\%)$ & $26(44 . \mathrm{I})$ \\
Previous $\beta$-blocker therapy, $\mathrm{n}(\%)$ & $12(20.3)$ \\
Previous diuretic therapy, $\mathrm{n}(\%)$ & $14(23.7)$ \\
Previous calcium channel blocker therapy, $\mathrm{n}(\%)$ & $8(13.6)$ \\
Coronary heart disease, $\mathrm{n}(\%)$ & $\mathrm{I}(\mathrm{I} .7)$ \\
History of heart failure, $\mathrm{n}(\%)$ & $2(3.4)$ \\
Renal dysfunction, $\mathrm{n}$ (\%) & $3(5 . \mathrm{I})$ \\
Cardiovascular disease in relatives, $\mathrm{n}(\%)$ & $22(37.3)$ \\
Smokers, $\mathrm{n}(\%)$ & $12(20.3)$ \\
PWVE, m/sec & $13.1 \pm 0.54$ \\
PWVM, m/sec & $9.7 \pm 0.6 \mathrm{I}$ \\
Central systolic BP, mmHg & $142.3 \pm 3.3$ \\
\hline
\end{tabular}

Abbreviations: $A C E$, angiotensin-converting enzyme; $A H$, arterial hypertension; BMI, body mass index; BP, blood pressure; HR, heart rate; PWVE, carotid-femoral pulse wave velocity; PWVM, radial pulse wave velocity.

pressure monitoring, pulse wave velocity, central systolic BP, potassium, sodium, creatinine, serum uric acid, alanine transaminase, aspartate transaminase, bilirubin, glucose, total cholesterol, triglycerides, low-density and high-density cholesterol, and electrocardiography.

Systolic and diastolic BP measurements (705 IT monitor, Omron Corporation, Kyoto, Japan) were recorded at screening, after a seven-day washout period, and at each clinic visit. $\mathrm{BP}$ was recorded as the average of three measurements taken at 1-2-minute intervals with the patient in the sitting position, according to the recommendations of the European Society of Hypertension. ${ }^{25}$ Heart rate was estimated after the second BP measurement. Electrocardiography was performed using a 12-channel electrocardiographic Unicard-200 (Utas company, Ukraine). Presence of arrhythmias and common signs of left ventricular hypertrophy was documented. ${ }^{26}$

Ambulatory blood pressure monitoring (ABPM-04 device, Meditech, Budapest, Hungary) was performed according to European Society of Hypertension recommendations, ${ }^{25}$ and recorded mean 24-hour, daytime, night-time, and maximal values for systolic and diastolic BP and heart rate, calculated the pressure load indices for systolic and diastolic BP, which were defined as a percentage of measurements $>140 / 90 \mathrm{mmHg}$ in the daytime and $120 / 80 \mathrm{mmHg}$ at night-time. Variability of systolic and diastolic BP were calculated as the standard deviation. In addition, the daily index was estimated, ie, the 
percentage of night-time BP reduction compared with the corresponding daytime BP. The morning surge was calculated as the difference between maximal BP at 6 am to noon and nadir BP during the night. Ambulatory blood pressure monitoring was carried out according to the following regimen: every 15 minutes during the day and every 30 minutes during the night ( $10 \mathrm{pm}$ to $6 \mathrm{am}$ ) Patients maintained their usual lifestyle during the study, as well as their normal levels of physical activity and psychoemotional stress. ${ }^{27}$

Blood chemistry was investigated using an automatic photometer (SABA, Cormay, Poland). Creatinine clearance was calculated using the Cockcroft-Gault equation. Routine blood and urine tests were performed at baseline to monitor drug safety.

Pulse wave velocity and central BP were measured using a Sphygmocor-PVx device (AtCor Medical Pty Ltd, West Ryde, NSW, Australia). Piezo sensors were positioned on the right common carotid, femoral, and radial arteries under direct vision and automated quality control was achieved using specialized device software. Pulse wave duration, pulse wave velocity, and central systolic BP were measured automatically using the device software after assessment of the distance between sensors (using a centimetric ribbon). Pulse wave velocity was estimated as both carotid-femoral (PWVE) and radial (PWVM). Augmentation index (AIx) and ejection time were also measured. .,21,23,28-35 $^{2}$

The primary endpoints of this study were: decrease in office BP, 24-hour BP, and central systolic BP, reaching target BP, decrease in PWVE and PWVM, and changes in AIx and ejection time. The secondary endpoints were factors correlated with central BP in both treatment groups.

\section{Treatment}

If patients were not on treatment at the time of screening, they were randomized to receive either a fixed-dose combination of losartan $100 \mathrm{mg}+$ HCTZ $25 \mathrm{mg}$ once daily (Lorista $\mathrm{HD}^{\circledR}$, KRKA, Novo Mesto, Slovenia) or a nonfixed combination of bisoprolol (Concor ${ }^{\circledR}$, Nycomed, Konstanz, Germany) 10 mg once daily + HCTZ (Sanofi-aventis, Paris, France) $25 \mathrm{mg}$ once daily. The first dose was taken in the office. Antihypertensive efficacy was assessed after 1 month of treatment. If BP was $\geq 140 / 90 \mathrm{mmHg}$, amlodipine (Tenox ${ }^{\circledR}$, KRKA) $5 \mathrm{mg}$ was added and then $10 \mathrm{mg}$ in the event of lack of effect by the second month of treatment. If BP was still $\geq 140 / 90 \mathrm{mmHg}$ by the third month of treatment, doxazosin (Cardura ${ }^{\circledR}$, Pfizer Inc, New York, NY, USA) 2-4 mg once daily was added (Figure 1).

Patients who had been taking antihypertensive drugs before entering the trial underwent a seven-day washout period, after which the inclusion criteria were reviewed. If patients met these criteria and there were no exclusion criteria, they were randomized as above. Concomitant therapy included lifestyle modification, statins, and acetylsalicylic acid, and the groups were comparable in this regard.

\section{Statistical analysis}

Statistical analysis was performed using Microsoft ${ }^{\circledR}$ Excel software. The data are expressed as the mean \pm standard deviation or as a percentage. All statistical calculations were performed using the Statistical Package for Social Sciences version 16.0 (SPSS Inc, Chicago, IL, USA). The statistical significance of differences between groups was estimated using the independent $t$-test of mean values, the Mann-

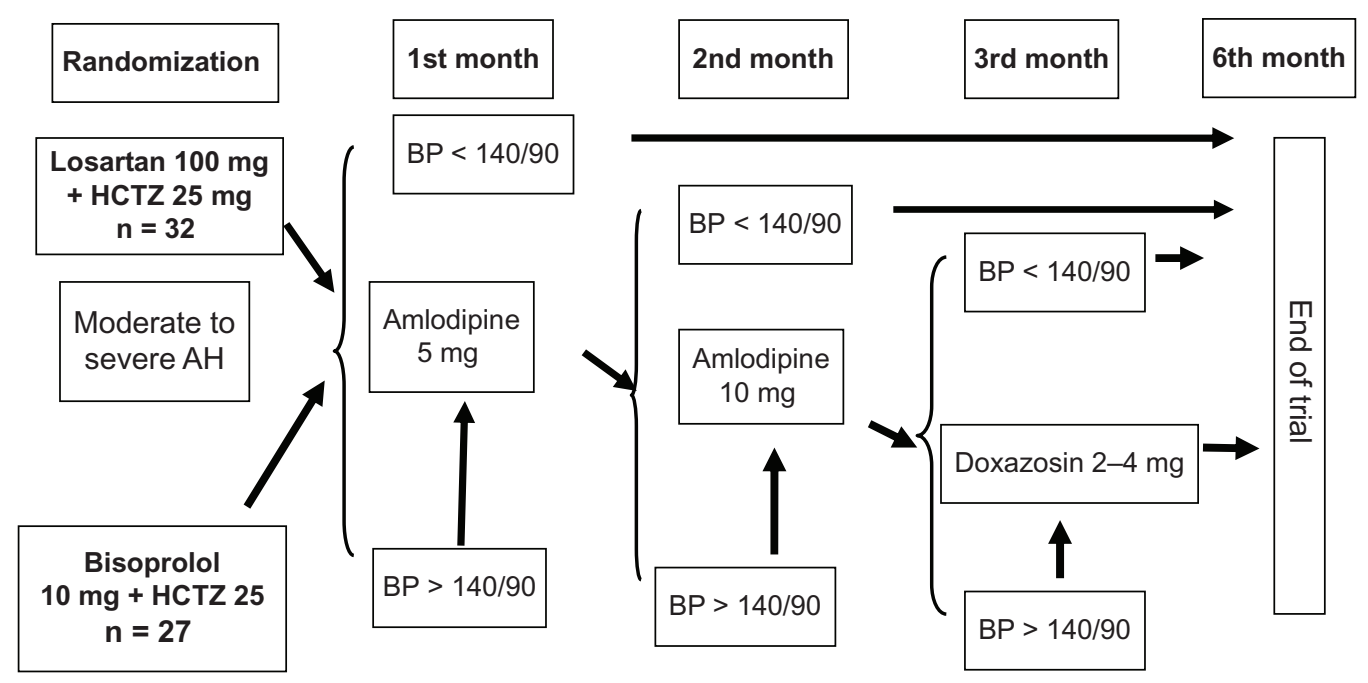

Figure I Treatment scheme.

Abbreviations: $\mathrm{AH}$, arterial hypertension; BP, blood pressure; HCTZ, hydrochlorothiazide. 
Whitney $U$ test (in the case of non-normal distribution) for continuous variables, and chi-square analysis for categorical variables. Comparison of changes on treatment was done using the paired two-samples $t$-test for means. Statistical significance was assumed at $P<0.05$. Correlative analysis was performed after determining the nature of distribution using the Spearman correlation test.

\section{Results}

The clinical and demographic characteristics of the two treatment groups are shown in Table 2 . There were no statistically significant differences between the groups with regard to demographic characteristics, BP at screening and randomization, and any therapy received by the patients before or after inclusion in the study. Changes in office BP and heart rate during the study are shown in Table 3 . There was a significant reduction in office systolic and diastolic BP in both groups. By the sixth month, office BP had decreased by a mean of

Table 2 Clinical and demographic characteristics according to treatment group

\begin{tabular}{|c|c|c|c|}
\hline Patterns & $\begin{array}{l}\text { Losartan }+ \\
\text { HCTZ group, } \\
\mathbf{n}=32\end{array}$ & $\begin{array}{l}\text { Bisoprolol + } \\
\text { HCTZ group, } \\
\mathbf{n}=\mathbf{2 7}\end{array}$ & $P$ \\
\hline Age, years & $56.2 \pm 2.04$ & $51.3 \pm 3.4$ & NS \\
\hline Women/men, n (\%) & $16(50) / 16(50)$ & $9(33.5) / / 8(66.7)$ & NS \\
\hline $\begin{array}{l}\text { Office systolic BP at } \\
\text { screening, } \mathrm{mmHg}\end{array}$ & $169.3 \pm 2.2$ & $164.5 \pm 2.4$ & NS \\
\hline $\begin{array}{l}\text { Office diastolic BP at } \\
\text { screening, } \mathrm{mmHg}\end{array}$ & $97.3 \pm 1.1$ & $97.7 \pm 1.2$ & NS \\
\hline BMI, $\mathrm{kg} / \mathrm{m}^{2}$ & $30.1 \pm 0.7$ & $29.9 \pm 1.8$ & NS \\
\hline $\begin{array}{l}\text { Office systolic } \mathrm{BP} \text { at } \\
\text { randomization, } \mathrm{mmHg}\end{array}$ & $174.4 \pm 1.1$ & $172.4 \pm 1.6$ & NS \\
\hline $\begin{array}{l}\text { Office diastolic } \mathrm{BP} \text { at } \\
\text { randomization, } \mathrm{mmHg}\end{array}$ & $99.3 \pm 1.04$ & $97.6 \pm 1.3$ & NS \\
\hline New diagnosed $\mathrm{AH}, \mathrm{n}(\%)$ & $17(53.0)$ & $17(62.9)$ & NS \\
\hline Smokers, n (\%) & $9(28.3)$ & $3(I I . I)$ & NS \\
\hline $\begin{array}{l}\text { Relatives with cardiovascular } \\
\text { disease, } n(\%)\end{array}$ & $13(40.6)$ & $9(33.5)$ & NS \\
\hline $\begin{array}{l}\text { Previous } \beta \text {-blocker } \\
\text { therapy, n (\%) }\end{array}$ & $9(28.1)$ & $3(11.1)$ & NS \\
\hline $\begin{array}{l}\text { Previous ACE inhibitor } \\
\text { therapy, } \mathrm{n}(\%)\end{array}$ & $15(46.9)$ & $9(33.5)$ & NS \\
\hline $\begin{array}{l}\text { Previous diuretic } \\
\text { therapy, } \mathrm{n}(\%)\end{array}$ & $10(31.3)$ & $4(14.8)$ & NS \\
\hline $\begin{array}{l}\text { Previous calcium channel } \\
\text { blockers, } \mathrm{n}(\%)\end{array}$ & $4(12.5)$ & $4(14.8)$ & NS \\
\hline $\begin{array}{l}\text { Addition of amlodipine } \\
5 \mathrm{mg}, \mathrm{n} \mathrm{( \% )}\end{array}$ & $27(84.4)$ & $20(74.1)$ & NS \\
\hline $\begin{array}{l}\text { Addition of amlodipine } \\
10 \mathrm{mg}, \mathrm{n}(\%)\end{array}$ & $16(50)$ & $16(59.3)$ & NS \\
\hline Addition of doxazosin, $\mathrm{n}(\%)$ & $2(6.3)$ & $3(11.1)$ & NS \\
\hline
\end{tabular}

Abbreviations: $\mathrm{ACE}$, angiotensin-converting enzyme; $\mathrm{AH}$, arterial hypertension; BMI, body mass index; BP, blood pressure; HCTZ, hydrochlorothiazide; NS, not statistically significant.
$44.7 \pm 0.9 / 18.4 \pm 1.1 \mathrm{mmHg}$ in the losartan $+\mathrm{HCTZ}$ group and by $42.2 \pm 1.1 / 16.5 \pm 0.8 \mathrm{mmHg}$ in the bisoprolol $+\mathrm{HCTZ}$ group. The difference in BP reduction between the treatment groups was not statistically significant. A reduction in heart rate was noted in both groups, but was more pronounced in the bisoprolol + HCTZ group.

Overall, a similar proportion of patients in the losartan + HCTZ and bisoprolol + HCTZ groups $(96.9 \%$ and $92.6 \%$, respectively) achieved their target office $\mathrm{BP}(<140 / 90 \mathrm{mmHg})$; the majority of patients also received amlodipine $5 \mathrm{mg}$ ( $84.4 \%$ and $74.1 \%$, respectively) and more than half required an increased dose of amlodipine (50.0\% and $59.3 \%$ ), reflecting the severity of hypertension in these patients. Only two patients $(6.3 \%)$ in the losartan + HCTZ group and three $(11.1 \%)$ in the bisoprolol + HCTZ group did not achieve their target BP after 6 months of treatment, and were referred on to exclude resistant or secondary hypertension as a result of renal artery stenosis, aldosteronism, or pheochromocytoma. These findings suggest that when clinicians prescribe aggressive antihypertensive therapy, regardless of drug type, target BP can be achieved in the majority of patients with uncomplicated moderate-to-severe hypertension.

The 24-hour BP monitoring data are shown in Figure 2. A significant and substantial reduction in 24-hour BP was achieved in the losartan + HCTZ group after 3 months of treatment, but not in the bisoprolol + HCTZ group. At the sixth month, a statistically significant reduction in BP was achieved in both groups (by 24.6 $\pm 1.3 / 17.6 \pm 1.1 \mathrm{mmHg}$ and by $24.1 \pm 1.8 / 16.9 \pm 1.2 \mathrm{mmHg}$ in the losartan + HCTZ group and bisoprolol + HCTZ group, respectively). The 24-hour heart rate did not change significantly in the losartan $+\mathrm{HCTZ}$ group, but decreased significantly in the bisoprolol + HCTZ by 12 beats per minute. Overall, $62.5 \%$ of patients in the losartan + HCTZ group and $51.9 \%$ of patients in the bisoprolol + HCTZ group achieved their target 24-hour BP at the third month of treatment, and $75 . \%$ and $66.7 \%$, respectively, by the sixth month (Table 4).

The results for ambulatory blood pressure monitoring are shown in Table 4. Maximal systolic BP decreased significantly in both groups, but a significant maximal diastolic BP reduction was noted only in the losartan + HCTZ group. Daytime and 24-hour systolic and diastolic BP decreased significantly in both groups after 6 months of treatment, but only in the losartan + HCTZ group after 3 months. There was a significant decrease in variability of daytime pulse pressure and daytime systolic BP in the losartan + HCTZ group but not in the bisoprolol + HCTZ group. The reduction in 


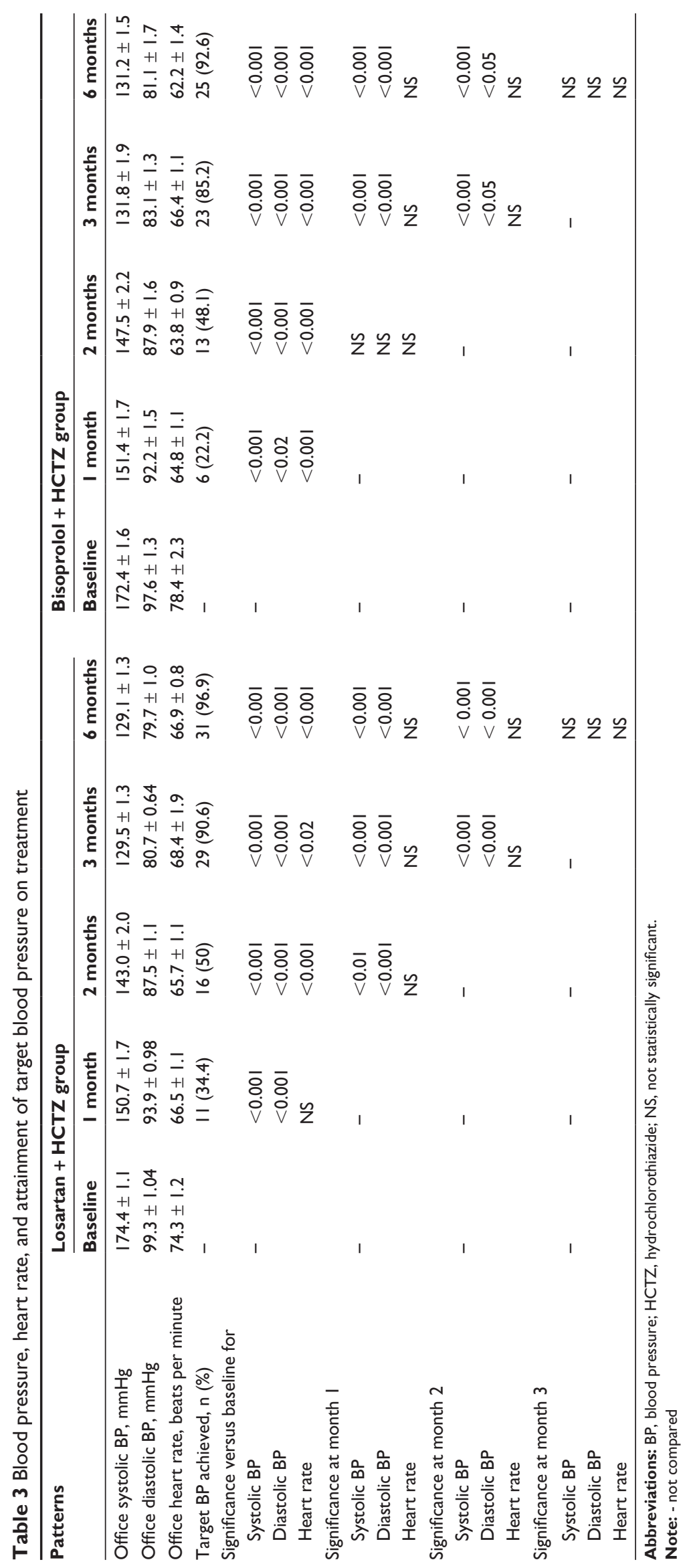




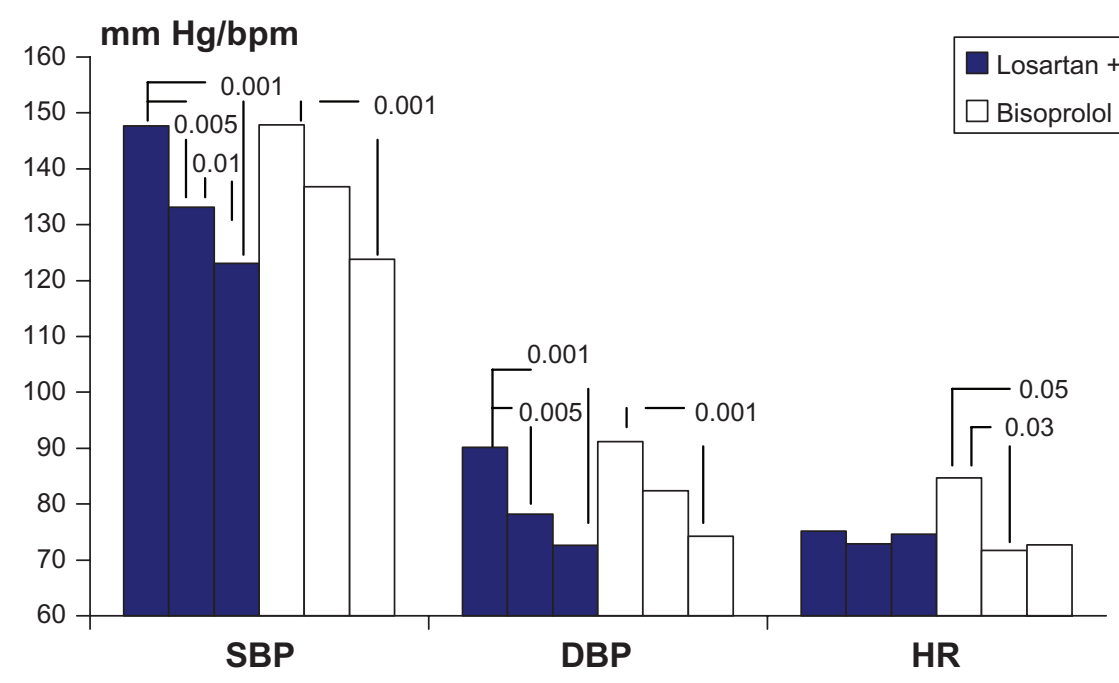

Figure 2 Changes in 24-hour SBP, DBP, and HR on treatment.

Abbreviations: DBP, diastolic blood pressure; SBP, systolic blood pressure; HCTZ, hydrochlorothiazide; HR, heart rate.

pulse pressure indirectly suggests an improvement in aortic stiffness. ${ }^{21}$ Reduction in variability of BP (initially higher than normal in both groups) could have a positive prognostic value, given that high variability is associated with an increased complication rate. ${ }^{27}$

The antihypertensive efficacy of both treatments was confirmed by a significant reduction in pressure load indices for 24-hour, daytime, and nighttime systolic and diastolic BP. No significant differences were found in regard to effects on the morning surge. Both drugs were administered once daily, and a significant reduction in the morning surge of systolic BP might have a positive influence on prognosis, because the morning surge has been shown to contribute to a higher cardiovascular event rate in the morning hours. ${ }^{36}$

Changes in arterial stiffness and central BP during the study are shown in Table 5. No significant changes in PWVE, PWVM, ejection time, or AIx were found in the losartan + HCTZ group. However, a significant increase in ejection time was documented in the bisoprolol + HCTZ group, indicating a prolongation of systole. AIx increased significantly in the bisoprolol + HCTZ group, and this could explain the $6.5 \mathrm{mmHg}$ difference in central systolic BP seen between the losartan + HCTZ and bisoprolol + HCTZ groups at the end of the study despite similar brachial artery BP. The changes in PWVE, PWVM, and AIx were significantly different between the losartan + HCTZ group and the bisoprolol + HCTZ group $(-0.63 \pm 0.09 \mathrm{~m} / \mathrm{sec}$, $0.46 \pm 0.08 \mathrm{~m} / \mathrm{sec}$, and $1.2 \% \pm 0.5 \%$, respectively, versus $0.1 \pm 0.1 \mathrm{~m} / \mathrm{sec},-0.91 \pm 0.10 \mathrm{~m} / \mathrm{sec}$, and $-4.7 \% \pm 0.4 \%$, $P<0.001$, Figure 3). These data indicate that arterial stiffness was improved to a greater extent by losartan + HCTZ than by bisoprolol + HCTZ.

Significant lowering of central systolic BP was observed in both groups, but the reduction was greater in the losartan + HCTZ group than in the bisoprolol + HCTZ group (Table 5, Figure 4). The $6.5 \mathrm{mmHg}$ difference in central systolic BP between the groups was not statistically significant, probably because of the small number of patients entered into the study. ASCOT included 2,199 patients, and the difference in central systolic BP between the groups was only $4.3 \mathrm{mmHg}$, but given the larger number of patients, the difference was statistically significant. ${ }^{37}$ Therefore, any effective antihypertensive therapy is associated with central BP reduction. However, with the same brachial BP reduction, losartan + HCTZ achieved a more marked decrease in central systolic BP than bisoprolol + HCTZ.

Factors associated with central systolic BP in the treatment groups are shown in Table 6. In the losartan + HCTZ group, central systolic BP was correlated with variability in daytime and nighttime pulse pressure, daytime systolic BP, body mass index, glucose level, and prior treatment with a calcium antagonist at the end of trial. However, in the bisoprolol + HCTZ group, central systolic BP correlated negatively only with heart rate, ie, the higher the heart rate, the lower the central systolic BP at the end of the study. Lowering of central systolic BP in the losartan + HCTZ group was associated only with central systolic BP at baseline and end of the study, whereas in the bisoprolol + HCTZ group it was associated with variability in daytime systolic and diastolic BP, office diastolic BP, serum glucose, and body mass index only at the end of the trial. 
Table 4 Changes in ambulatory blood pressure monitoring data in the two treatment groups

\begin{tabular}{|c|c|c|c|c|c|c|}
\hline \multirow[t]{2}{*}{ Patterns } & \multicolumn{3}{|c|}{ Losartan + HCTZ } & \multicolumn{3}{|c|}{ Bisoprolol + HCTZ } \\
\hline & Baseline & 3 months & 6 months & Baselines & 3 months & 6 months \\
\hline Maximum 24-hour SBP, mmHg & $184.7 \pm 8.1$ & $173.8 \pm 14.7$ & $158.2 \pm 4.1 *$ & $188.8 \pm 6.4$ & $174.8 \pm 6.8$ & $161.7 \pm 6.7^{*}$ \\
\hline Maximum 24-hour DBP, mmHg & $113.2 \pm 3.8$ & $102.6 \pm 7.2^{* * *}$ & $103.3 \pm 2.9^{* * * *}$ & $111.4 \pm 7.3$ & $112.8 \pm 5.6$ & $110.1 \pm 6.5$ \\
\hline 24-hour pulse pressure, $\mathrm{mmHg}$ & $59.3 \pm 2.8$ & $59.9 \pm 4.6$ & $51.3 \pm 3.1$ & $53.8 \pm 2.4$ & $51.2 \pm 6.5$ & $48.7 \pm 2.9$ \\
\hline Daily index SBP, \% & $7.9 \pm 1.6$ & $8.7 \pm 1.5$ & $7.9 \pm 1.7$ & $9.5 \pm 2.3$ & $8.9 \pm 1.5$ & $7.2 \pm 1.8$ \\
\hline Daily index DBP, \% & $11.4 \pm 1.9$ & $13.6 \pm 2.2$ & $12.0 \pm 1.6$ & $11.7 \pm 1.9$ & $11.5 \pm 2.3$ & $12.8 \pm 2.8$ \\
\hline Pressure load, 24-hour SBP, \% & $69.0 \pm 5.4$ & $49.5 \pm 6.9 * * *$ & $23.7 \pm 4.5^{*}$ & $74.7 \pm 5.6$ & $56.4 \pm 7.5^{*}$ & $25.9 \pm 7.4^{*}$ \\
\hline Pressure load, 24-hour DBP, \% & $44.2 \pm 6.5$ & $21.9 \pm 6.0 * *$ & $\mid 3.1 \pm 2.8^{*}$ & $58.8 \pm 9.9$ & $35.9 \pm 8.1 * *$ & $\mid 5.1 \pm 6 . I^{*}$ \\
\hline Daytime SBP, mmHg & $148.9 \pm 3.5$ & $137.3 \pm 3.1 * *$ & $125.9 \pm 2.6^{* . \wedge}$ & $|5| . \mid \pm 4.2$ & $140.3 \pm 4.1$ & $\mid 25.8 \pm 4 . I^{* \wedge \wedge}$ \\
\hline Daytime DBP, $\mathrm{mmHg}$ & $97.1 \pm 2.6$ & $80.9 \pm 2.9 *$ & $75.2 \pm 1.8^{*}$ & $95.2 \pm 4.0$ & $85.7 \pm 3.5$ & $78.4 \pm 2.7^{*}$ \\
\hline Daytime HR, beats per minute & $72.9 \pm 2.0$ & $77.3 \pm 2.9$ & $78.0 \pm 2.5$ & $83.9 \pm 3.5^{\#}$ & $76.3 \pm 3.8$ & $77.6 \pm 3.3$ \\
\hline Daytime pulse pressure, $\mathrm{mmHg}$ & $58.7 \pm 2.6$ & $62.3 \pm 5.9$ & $50.7 \pm 2.2 * * *$ & $54.6 \pm 2.6$ & $54.6 \pm 3.4$ & $47.4 \pm 2.0$ \\
\hline Daytime SBP variability, $\mathrm{mmHg}$ & $16.7 \pm 0.9$ & $13.2 \pm 0.8^{*}$ & $13.7 \pm 0.9 * * *$ & $16.6 \pm 1.3$ & $13.8 \pm 1.0$ & $14.5 \pm 1.8$ \\
\hline Daytime DBP variability, $\mathrm{mmHg}$ & $12.3 \pm 0.7$ & $10.9 \pm 0.7$ & $10.7 \pm 0.7$ & $11.6 \pm 1.1$ & $10.4 \pm 0.6$ & $12.4 \pm 1.2$ \\
\hline Pressure load, daytime SBP, \% & $63.5 \pm 6.0$ & $46.1 \pm 7.7$ & $17.2 \pm 4.7^{*, \Lambda}$ & $68.9 \pm 6.7$ & $47.9 \pm 8.1$ & $20.7 \pm 8.4^{*, \wedge \wedge}$ \\
\hline Pressure load, daytime DBP, \% & $44.0 \pm 6.3$ & $23.2 \pm 7.2^{* * *}$ & $12.3 \pm 2.9^{*}$ & $60.4 \pm 9.7$ & $36.6 \pm 9.0$ & $18.4 \pm 7.1^{*}$ \\
\hline Nighttime SBP, mmHg & $136.5 \pm 4.5$ & $125.8 \pm 3.1$ & $117.3 \pm 3.5^{*}$ & $\mid 40.1 \pm 4.1$ & $130.7 \pm 3.7$ & $117.3 \pm 4.2^{*, \wedge \wedge}$ \\
\hline Nighttime DBP, mmHg & $83.4 \pm 2.7$ & $69.9 \pm 1.9 *$ & $66.0 \pm 1.5^{*}$ & $85.9 \pm 3.5$ & $75.3 \pm 2.6^{* * *, \#}$ & $66.9 \pm 2.7^{*}$ \\
\hline Nighttime pulse pressure, $\mathrm{mmHg}$ & $60.1 \pm 3.7$ & $56.4 \pm 3.1$ & $51.3 \pm 2.7$ & $52.0 \pm 2.9$ & $55.4 \pm 3.4$ & $50.4 \pm 2.6$ \\
\hline Nighttime HR, beats per minute & $74.8 \pm 3.3$ & $67.6 \pm 2.5$ & $69.3 \pm 2.5$ & $78.2 \pm 3.8$ & $65.6 \pm 3.8$ & $67.5 \pm 2.1 * * *$ \\
\hline Nighttime SBP variability, $\mathrm{mmHg}$ & $15.9 \pm 1.5$ & $12.7 \pm 1.3$ & $13.6 \pm 1.1$ & $11.9 \pm 1.3^{\#}$ & $14.8 \pm 1.6$ & $12.6 \pm 2.1$ \\
\hline Nighttime DBP variability, $\mathrm{mmHg}$ & $10.4 \pm 0.8$ & $9.2 \pm 0.8$ & $10.3 \pm 0.9$ & $8.4 \pm 1.2$ & $10.4 \pm 1.6$ & $9.6 \pm 1.3$ \\
\hline Pressure load, nighttime SBP, \% & $73.5 \pm 6.2$ & $54.1 \pm 7.6$ & $37.4 \pm 6.5^{*}$ & $85.1 \pm 5.2$ & $7 I .1 \pm 8.4$ & $36.2 \pm 10.1^{*}$ \\
\hline Pressure load, nighttime DBP, \% & $33.7 \pm 7.1$ & $15.7 \pm 5.1 * * *$ & $11.7 \pm 3.2^{*}$ & $60.4 \pm 8.9$ & $33.6 \pm 7.7^{* * *}$ & $10.6 \pm 6.7^{*}$ \\
\hline Morning surge $\mathrm{SBP}, \mathrm{mmHg}$ & $65.6 \pm 6.6$ & $43.6 \pm 5.5^{* *}$ & $42.1 \pm 2.6^{*}$ & $67.7 \pm 6.5$ & $48.3 \pm 5.6 * * *$ & $38.7 \pm 6.0 * *$ \\
\hline Morning surge DBP, $\mathrm{mmHg}$ & $35.4 \pm 5.9$ & $26.1 \pm 4.7$ & $33.8 \pm 2.5$ & $33.7 \pm 4.3$ & $34.7 \pm 4.0$ & $29.3 \pm 5.6$ \\
\hline Target 24-hour BP, n (\%) & - & $20(62.5)$ & $24(75.0)^{\wedge}$ & - & $14(5 \mid .9)$ & $18(66.7)^{\wedge \wedge}$ \\
\hline
\end{tabular}

Notes: $* P<0.01 ; * * P<0.02 ; * * * P<0.05$ versus baseline in same group; $\wedge P<0.01 ; \wedge \wedge P<0.05$ versus month 3 in same group; $\# P<0.05$ versus losartan $+\mathrm{HCTZ}$ group. Abbreviations: DBP, diastolic blood pressure; SBP, systolic blood pressure; HCTZ, hydrochlorothiazide; HR, heart rate.

Because body mass index and serum glucose levels correlated directly with the central systolic BP achieved in the losartan + HCTZ group and negatively in the bisoprolol + HCTZ group, it appears that lifestyle modification is required for optimal control of central BP.

As mentioned above, central systolic BP was correlated with heart rate in the bisoprolol + HCTZ group but not in the losartan + HCTZ group. Therefore, we investigated the influence of heart rate on central systolic BP and arterial stiffness at baseline and during treatment. Mean baseline heart rate in the study population was 74.4 beats per minute. Patients were divided into two subgroups, ie, one with a heart rate $\geq$ 75 beats per minute and the other with a heart rate $<75$ beats per minute. There was no significant difference in the study parameters between these subgroups at baseline (Table 7). Mean heart rate in the study population was 66.6 beats per

Table 5 Changes in arterial stiffness patterns and central SBP in treatment groups

\begin{tabular}{|c|c|c|c|c|}
\hline \multirow[t]{2}{*}{ Patterns } & \multicolumn{2}{|c|}{ Losartan + HCTZ, n = 32} & \multicolumn{2}{|c|}{ Bisoprolol + HCTZ, n = 27} \\
\hline & Baseline & End of study & Baseline & End of study \\
\hline PVWE, $\mathrm{m} / \mathrm{sec}$ & $13.2 \pm 0.5$ & $12.7 \pm 0.5$ & $13.1 \pm 0.7$ & $13.0 \pm 0.5$ \\
\hline PVWM, m/sec & $9.5 \pm 0.6$ & $9.1 \pm 0.5$ & $10.5 \pm 0.49$ & $11.5 \pm 0.6$ \\
\hline ET, \% & $35.3 \pm 1.8$ & $38.2 \pm 2.7$ & $32.2 \pm 1.3$ & $36.7 \pm 1.3^{*}$ \\
\hline Alx, \% & $23.1 \pm 1.8$ & $21.9 \pm 3.1$ & $19.7 \pm 1.7$ & $24.6 \pm 1.5^{*}$ \\
\hline Central SBP, mmHg & $144.6 \pm 3.1$ & $121.6 \pm 2.5^{* *}$ & $\mid 42.1 \pm 3.3$ & $\mid 28.1 \pm 2.4^{* *}$ \\
\hline$\Delta$ Central SBP, $\mathrm{mmHg}$ & $-23.0 \pm 2.3$ & & $-15.4 \pm 2.9^{\#}$ & \\
\hline
\end{tabular}

Notes: $* P<0.05 ; * P<0.001$, statistically significant versus baseline; ${ }^{*} P<0.05$, statistically significant between groups.

Abbreviations: Alx, augmentation index; ET, ejection time; HCTZ, hydrochlorothiazide; SBP, systolic blood pressure; PWVE, carotid-femoral pulse wave velocity; PWVM, radial pulse wave velocity. 


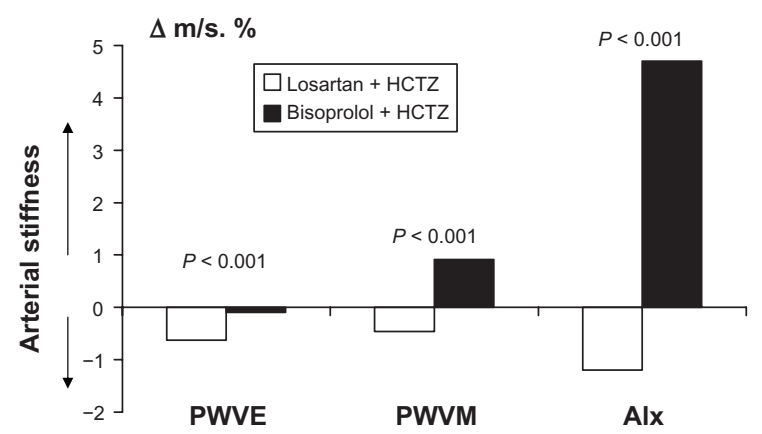

Figure 3 Changes in arterial stiffness patterns $(\Delta)$ in treatment groups. Abbreviations: PWVE, carotid-femoral pulse wave velocity; PWVM, radial pulse wave velocity; Alx, augmentation index.

minute at the end of the study. Patients were divided again into subgroups, ie, one with a heart rate $<67$ beats per minute and the other with a heart rate $\geq 67$ beats per minute. We noted that a lower heart rate on treatment was associated with higher PWVE, AIx, and central systolic BP.

We also compared the influence of changes in heart rate between the treatment groups (Table 8). In ASCOT, the relationship between central BP and heart rate was investigated during treatment, but not before randomization, and we did not find similar analyses in any of the other relevant studies. It appeared that in the losartan $+\mathrm{HCTZ}$ group there were no significant differences between the study parameters depending on heart rate achieved, except for an increase in PWVE when heart rate decreased $(P=0.026)$. Significant differences were observed in PWVE, ejection time, and AIx between the heart rate subgroups in patients receiving bisoprolol $+\mathrm{HCTZ}$, with values being significantly lower in those with a heart rate $\geq 67$ beats per minute. Mean heart rate on treatment did not differ significantly between corresponding subgroups in the two treatment groups.

\section{Tolerability}

The trial medication was well tolerated. Adverse reactions were observed in three patients $(9.4 \%)$ on losartan + HCTZ

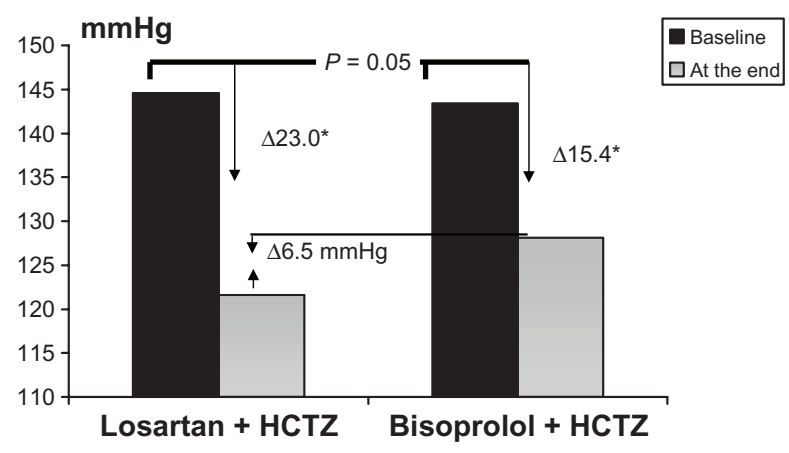

Figure 4 Changes in central systolic blood pressure in treatment groups. Note: *Statistically significant versus baseline. Abbreviation: HCTZ, hydrochlorothiazide. during the first month, all of whom had headache, which was probably associated with BP elevation rather than the treatment itself. These side effects did not warrant cessation of treatment. After 3 months, side effects were observed in eight $(25 \%)$ patients, three of whom experienced headache during the second month of treatment, and two patients developed ankle edema after addition of amlodipine. None of these side effects led to discontinuation of treatment, given that the ankle edema was mild and antihypertensive efficacy was high. After 6 months of treatment, one further patient developed ankle edema, giving an adverse event rate in the losartan + HCTZ group of $28.1 \%$.

Adverse reactions were observed in 10 patients (37\%) in the bisoprolol + HCTZ group, four of whom experienced headache during the first month of treatment, which was attributed to BP elevation; two patients had a heart rate $<$ 50 beats per minute requiring reduction in the $\beta$-blocker dose to $5 \mathrm{mg}$ once daily; one patient reported peripheral coldness, which disappeared after addition of amlodipine; and three patients had peripheral edema severe enough to require discontinuation of therapy. At 6 months, side effects were observed in $12(44.4 \%)$ patients (not statistically significant versus the losartan + HCTZ group); one further patient experienced edema and one experienced facial flushing, which was probably attributable to amlodipine. No significant changes in biochemical parameters were documented in either treatment group. Both treatments were well tolerated over 6 months of therapy, but the incidence of side effects was 1.6-fold lower in the losartan + HCTZ group.

\section{Discussion}

Arterial stiffness depends on arterial wall structure and distension pressure, which are defined by mean BP. ${ }^{38,39}$ Cardiac output initiates the pulse wave, which extends peripherally. At sites with the highest resistance (mainly arterioles), the pulse wave reflection moves back to the heart, meeting the direct wave. Summation of two waves, direct and repelled, determines the form of the resulting wave. Arterial stiffness, amplitude, and duration of cardiac output, characteristics of pulse wave reflection (time of direct and back spreading, site of reflection) determine the form of the resulting pulse wave. In young people, the waves meet in diastole, so systolic BP depends only on cardiac output. However, in older people, the pulse wave returns more rapidly, and wave summation occurs in systole, leading to a further increase in systolic BP, placing the heart under a higher load. 
Table 6 Central blood pressure and its correlations (Spearman) baseline and at the end of trial in dependence on treatment

\begin{tabular}{|c|c|c|}
\hline $\begin{array}{l}\text { Patterns/r, } \\
\text { significance }\end{array}$ & Losartan + HCTZ & Bisoprolol + HCTZ \\
\hline $\begin{array}{l}\text { End central } \\
\text { SBP }\end{array}$ & $\begin{array}{l}\text { End dPBP } 0.53, P=0.006 \\
\text { End nPBP } 0.54, P=0.024 \\
\text { End dSBP variability } 0.47 \\
P=0.018 \\
\text { End glucose level } 0.38 \\
P=0.05 \\
\text { Previous calcium } \\
\text { antagonist treatment } 0.36 \\
P=0.042 \\
\text { BMI } 0.33, P=0.05\end{array}$ & $\mathrm{HR}-0.5 \mathrm{I}, P=0.045$ \\
\hline $\begin{array}{l}\Delta \text { Central } \\
\text { systolic BP }\end{array}$ & $\begin{array}{l}\text { Baseline central SBP } 0.53 \\
P=0.002 \\
\text { End central SBP }-0.60 \\
P<0.00 \text { I }\end{array}$ & $\begin{array}{l}\text { End daytime SBP } \\
\text { variability }-0.78, P=0.013 \\
\text { End DI DBP } 0.71, P=0.022 \\
\text { Baseline office DBP } 0.59, \\
P=0.01 \\
\text { Baseline glucose }-0.54, \\
P=0.039 \\
\text { Baseline central SBP } 0.54, \\
P=0.026 \\
\text { BMI }-0.47, P=0.055\end{array}$ \\
\hline
\end{tabular}

Abbreviations: $\mathrm{dPBP}$, day time pulse blood pressure; $\mathrm{nPBP}$, night time pulse blood pressure; dSBP, day time systolic blood pressure; HR, heart rate, DI, daily index. BMI, body mass index; HCTZ, hydrochlorothiazide; DBP, diastolic blood pressure; SBP, systolic blood pressure; PWVE, carotid-femoral pulse wave velocity; PWVM, radial pulse wave velocity.

While systolic BP depends partially on pulse wave reflection, ${ }^{40}$ it may vary in different segments of the arterial tree. Thus, aortic BP may differ from systolic BP when measured at the brachial artery. This difference may vary from $1 \mathrm{mmHg}$ to $33 \mathrm{mmHg} .{ }^{41,42}$ Due to summation ("amplification") in young and tall individuals, peripheral systolic BP may be higher than normal, while central systolic BP may be normal. ${ }^{24}$ This can lead to overdiagnosis of hypertension and have an influence on the choice of future occupation in young people. In contrast, a decrease in brachial BP during therapy may not correspond to central $\mathrm{BP}$ reduction in the elderly. At the same brachial BP, central systolic BP may vary substantially, leading to underestimation of cardiovascular risk with increased aortic systolic BP.
Clinical trials have shown that central systolic BP and pulse pressure are more useful for prognostic purposes than brachial artery BP. ${ }^{12-14,30,35,43-50}$ The CAFE (Conduit Artery Function Evaluation) trial showed that increased central pulse BP was associated with a worse prognosis independently of other risk factors. ${ }^{14,45-47,50}$ Comparative analysis of groups with and without a history of cardiovascular complications in the Strong Heart Study showed that central pulse BP $>50 \mathrm{mmHg}$, but not brachial pulse BP, was an independent predictor of cardiovascular events. ${ }^{12,13}$ Further, SAFIHRE (the Study of Atrial Fibrillation in High Risk Elderly) demonstrated that central but not peripheral BP was associated with atrial fibrillation in 800 elderly patients ( $>65$ years) during $1.5 \pm 1.1$ years of follow-up. ${ }^{51}$ In addition to vascular complications, central pulse pressure and systolic BP determined target organ damage (left ventricular hypertrophy, intima media thickness, left ventricular diastolic dysfunction, increased left atrial size) and progression of atherosclerosis. ${ }^{12,44,52}$ Concomitant diseases such as coronary heart disease, diabetes mellitus, obstructive sleep apnea syndrome, dyslipidemia, and smoking increase central BP. ${ }^{53}$ There are also some racial differences, whereby young black individuals have higher central BP than whites, which could explain certain ethnic differences in cardiovascular event rates.

Several studies have shown that various antihypertensive drugs have different effects on cardiovascular complication rates despite having the same influence on brachial BP. $^{31,33,34,54-65}$ This observation has prompted consideration of the potential "BP-independent" effects of some drugs, and many short-term studies have shown that antihypertensive drugs had different effects on the pulse wave form despite having an equal effect on brachial BP. Lack of largescale trial data concerning the effect of different antihypertensive drugs on central BP initially raised discussion about the "uniqueness" of some of these agents, but this subsided after publication of the results of CAFE, which showed that the different influence of two treatment regimens (based

Table 7 Arterial stiffness patterns and central SBP according to heart rate

\begin{tabular}{|c|c|c|c|c|c|c|}
\hline \multirow[t]{2}{*}{ Patterns } & \multicolumn{2}{|l|}{ Baseline HR } & \multirow[t]{2}{*}{$P$} & \multicolumn{2}{|c|}{ HR on treatment } & \multirow[t]{2}{*}{$P$} \\
\hline & $\geq 75, n=31$ & $<75, \mathrm{n}=\mathbf{2 8}$ & & $\geq 67, \mathrm{n}=22$ & $<67, \mathbf{n}=\mathbf{3 7}$ & \\
\hline PWVE, $\mathrm{m} / \mathrm{s}$ & $13.4 \pm 0.59$ & $13.6 \pm 0.8$ & NS & $11.8 \pm 0.5$ & $13.5 \pm 0.5$ & 0.029 \\
\hline PWVM, m/c & $9.5 \pm 0.8$ & $9.8 \pm 0.6$ & NS & $9.9 \pm 0.3$ & $10.6 \pm 0.4$ & NS \\
\hline $\mathrm{ET}, \%$ & $35.8 \pm 1.1$ & $34.3 \pm 0.9$ & NS & $35.4 \pm 0.9$ & $38.9 \pm 4.0$ & NS \\
\hline Alx, \% & $24.1 \pm 3.5$ & $24.3 \pm 2.8$ & NS & $19.7 \pm 1.9$ & $25.8 \pm 1.4$ & 0.05 \\
\hline Central systolic BP & $144.2 \pm 3.8$ & $145.4 \pm 4.6$ & NS & $118.3 \pm 2.9$ & $127.6 \pm 2.9$ & 0.031 \\
\hline
\end{tabular}

Abbreviations: Alx, augmentation index; ET, ejection time; BP, blood pressure; HR, heart rate; PWVE, carotid-femoral pulse wave velocity; PWVM, radial pulse wave velocity; NS, not statistically significant. 
Table 8 Arterial stiffness patterns and central SBP according to heart rate and treatment

\begin{tabular}{|c|c|c|c|c|c|c|}
\hline \multirow[t]{4}{*}{ Patterns } & \multirow{2}{*}{\multicolumn{2}{|c|}{$\begin{array}{l}\text { Losartan + HCTZ } \\
\text { End HR }\end{array}$}} & \multirow[t]{4}{*}{$P$} & \multirow{2}{*}{\multicolumn{2}{|c|}{$\begin{array}{l}\text { Bisoprolol + HCTZ } \\
\text { End HR }\end{array}$}} & \multirow[t]{4}{*}{$P$} \\
\hline & & & & & & \\
\hline & $\geq 67$ & $<67$ & & $\geq 67$ & $<67$ & \\
\hline & $n=15$ & $n=17$ & & $n=7$ & $\mathbf{n}=\mathbf{2 0}$ & \\
\hline PWVE, $\mathrm{m} / \mathrm{sec}$ & $11.4 \pm 0.7$ & $13.4 \pm 0.8$ & NS & $11.7 \pm 0.4$ & $13.5 \pm 0.6$ & 0.05 \\
\hline PWVM, m/sec & $9.5 \pm 0.4$ & $10.3 \pm 0.5$ & NS & $10.9 \pm 0.58$ & $\mathrm{II} . \mathrm{I} \pm 0.8$ & NS \\
\hline ET, \% & $41.6 \pm 5.6$ & $35.4 \pm 1.1$ & NS & $33.0 \pm 2.0$ & $40.3 \pm 1.8$ & 0.02 \\
\hline Alx, \% & $20.6 \pm 2.4$ & $23.8 \pm 3.3$ & NS & $17.9 \pm 3.6$ & $29.7 \pm 2.3$ & 0.019 \\
\hline Central SBP, mmHg & $119.0 \pm 2.8$ & $123.8 \pm 3.2$ & NS & $119.7 \pm 2.7$ & $|35| \pm 5.2$. & 0.02 \\
\hline$\Delta \mathrm{PWVE}, \mathrm{m} / \mathrm{sec}$ & $-2.0 \pm 0.3$ & $0.73 \pm 0.7$ & 0.026 & $-0.7 \pm 0.54^{\#}$ & $0.18 \pm 0.9$ & NS \\
\hline$\Delta \mathrm{PWVM}, \mathrm{m} / \mathrm{sec}$ & $-0.45 \pm 1.1$ & $0.46 \pm 1.3$ & NS & $0.17 \pm 0.63$ & $-1.36 \pm 0.8$ & NS \\
\hline$\Delta$ Alx,$\%$ & $-2.7 \pm 2.9$ & $0.23 \pm 2.4$ & NS & $-1.6 \pm 5.9$ & $2.1 \pm 4.4$ & NS \\
\hline$\Delta$ Central SBP, mmHg & $-24.1 \pm 5.7$ & $-22.1 \pm 4.0$ & NS & $-20.0 \pm 2.6$ & $-11.3 \pm 2.4$ & 0.05 \\
\hline $\mathrm{HR}$, beats per minute & $7 I .1 \pm 0.7$ & $63.4 \pm 0.59$ & 0.001 & $71.7 \pm 1.6$ & $62.3 \pm 0.93$ & 0.001 \\
\hline$\Delta \mathrm{HR}$, beats per minute & $1.48 \pm 2.0$ & $-11.4 \pm 3.8$ & 0.009 & $4.3 \pm 3.3$ & $-21.6 \pm 4.5$ & 0.001 \\
\hline
\end{tabular}

Note: ${ }^{\# S i g n i f i c a n t ~ v e r s u s ~ l o s a r t a n ~}+$ HCTZ group.

Abbreviations: Alx, augmentation index; ET, ejection time; HCTZ, hydrochlorothiazide; HR, heart rate; SBP, systolic blood pressure; PWVE, carotid-femoral pulse wave velocity; PWVM, radial pulse wave velocity; NS, not statistically significant.

on atenolol and amlodipine) on prognosis was due to their different effects on central BP and pulse wave morphology. Further randomized studies have emerged, demonstrating certain advantages of some drugs over others in terms of their ability to reduce central systolic BP and central pulse pressure. More detailed analysis of the LIFE trial identified a difference in pulse BP reduction between the treatment groups in favor of losartan. ${ }^{4}$ Hirata et al compared ramipril with atenolol and showed that ramipril reduced aortic BP by $5 \mathrm{mmHg}$ more than atenolol, which casts some doubt over the results of the HOPE trial concerning the beneficial effects of ramipril over and above its ability to reduce $\mathrm{BP}^{66}$

The REASON (Preterax in Regression of Arterial Stiffness in a Controlled Double-Blind) trial demonstrated that the effect of antihypertensive therapy on systolic BP depended on several factors, including the elastic properties of the arterial walls, and that PWVE appeared to be an independent predictor of response to treatment. ${ }^{33,63} \mathrm{PWVE}$ is mainly associated with arterial wall structure and mean BP (distension pressure), so a decrease in PWVE should be associated with a reduction in central systolic BP.

PWVE is strongly associated with several cardiovascular risk factors, including smoking, high cholesterol, diabetes mellitus, hypertension, and a sedentary lifestyle. ${ }^{12,28,29,67-72}$ In hypertensives, PWVE and its changes on treatment are independent predictors of cardiovascular risk and total mortality, ${ }^{1,28,34,71,73-78}$ with a $5 \mathrm{~m} / \mathrm{sec}$ increase in PWVE corresponding to a 1.34 -fold increased risk of death and a 1.51-fold increased risk of cardiovascular mortality. However, it should be noted that a $5 \mathrm{~m} /$ sec change is a very significant fluctuation, given that, in healthy individuals aged 24-62 years, mean PWVE is $6-10 \mathrm{~m} / \mathrm{sec}^{23}$ In hypertensive patients with no other signs of cardiovascular disease, PWVE is a predictor of complications, ${ }^{1,54,60,68,78,79}$ so is a classic independent risk factor. In the two trials it has shown that the prognosis in patients with PWVE $>12 \mathrm{~m} / \mathrm{sec}$ and $>20 \mathrm{~m} / \mathrm{sec}$ is particularly poor. ${ }^{28,39,74,77}$ In diabetic patients with the same BP, mortality has been shown to be higher in those with PWVE than in the general population. ${ }^{30}$ Patients with renal insufficiency are at very high risk of cardiovascular events and death, and lowering of the pulse wave velocity by $1 \mathrm{~m} / \mathrm{sec}$ has been associated with a $29 \%$ reduction in overall mortality. ${ }^{28,33,35,39,74}$ Therefore, studying the effects of antihypertensive agents on central BP and arterial elasticity may be a promising area of research, ${ }^{42}$ and the results could be used to develop new treatment strategies tailored to each individual patient's risk profile.

As demonstrated in our study, a variety of antihypertensive agents can achieve different degrees of reduction in central systolic BP and have different effects on arterial stiffness with the same brachial BP reduction. ASCOT demonstrated that the lower the heart rate, the higher central systolic BP. This could explain why $\beta$-blockers have limited ability to reduce central systolic BP. In ASCOT, a decrease in heart rate of 10 beats per minute corresponded to a $3 \mathrm{mmHg}$ increase in central systolic BP and a $2.5 \%$ increase in AIx. ${ }^{14}$ There are three main reasons for this finding. First, reduction in heart rate leads to prolongation of systole, and the reflected pulse wave returns in systole, summates with the direct wave, and in turn 
increases central systolic BP. Second, $\beta$-blockers can induce peripheral vasoconstriction, thereby shifting the pulse wave reflection site proximally so that the pulse wave returns earlier. Increased vascular resistance can also augment the pulse wave amplitude. Third, according to the Poiseuille equation: $\mathrm{BP}=$ cardiac output $\times$ peripheral resistance, where output is systolic volume $\times$ heart rate. When heart rate decreases during therapy, mean BP is sustained by increasing systolic volume. This phenomenon is observed frequently in patients with complete atrioventricular block.

In younger patients with more elastic capacitance vessels, increased systolic volume does not induce significant BP elevation because these vessels can dilate. Therefore, resistance and BP both decrease. In elderly people and in those with hypertension or atherosclerosis, a reduction in heart rate causes an increase in systolic volume that is not compensated for by dilation of the capacitance vessels (because of age-related and pathological changes in the arterial wall), which in turn leads to elevated central systolic BP and pulse pressure. In other words, any drug that reduces heart rate may be less effective in reducing central BP. However, there is some evidence that blockers with vasodilatory properties are more effective than $\beta$-blockers without these properties in reducing central systolic BP. ${ }^{54,79}$ Matsui et al reported a more marked decrease in central BP and heart rate in patients on olmesartan + azelnidipine than in those on olmesartan + HCTZ. ${ }^{60}$ The authors attributed this to the more marked positive effect of olmesartan + azelnidipine on peripheral resistance and PWVE, regardless of the decrease in heart rate. Therefore, there may be an additional beneficial effect from antihypertensive drugs that neutralize the effect of the decrease in heart rate, ie, favorable effects on stiffness in capacitance vessels, endothelial function, and peripheral vasodilatation. $^{80}$

In ASCOT, a reduction in heart rate of 10 beats per minute corresponded to an increase in central systolic BP of $3 \mathrm{mmHg}$. The average heart rate (based on office BP measurement) decreased by $5.9 \pm 1.6$ beats per minute in the losartan + HCTZ group and by $12.9 \pm 3.9$ beats per minute in the bisoprolol + HCTZ group. Thus, the difference in heart rate between the two groups was 7 beats per minute, which should have achieved a difference in central systolic BP of more than $3 \mathrm{mmHg}$ (in our trial the difference was $6.5 \mathrm{mmHg}$ ). Moreover, in our trial, central systolic BP on treatment was not correlated with reduction in heart rate, but only with the heart rate achieved, indicating that only losartan + HCTZ neutralized the effect of decreased heart rate on central systolic $\mathrm{BP}$.
A significant $4.7 \%$ increase in AIx was observed in our bisoprolol + HCTZ group which could have been triggered by the reduction in heart rate. According to Wilkinson et al, a reduction in heart rate of 10 beats per minute from an initial value of 75 beats per minute was associated with a $3.9 \%$ increase in AIx. ${ }^{37}$ In our bisoprolol + HCTZ group, heart rate decreased to 62.2 beats per minute, ie, 13 beats per minute less than initial value of 75 beats per minute, which might have caused the $4.7 \%$ increase in AIx. Therefore, our data are consistent with the current literature. In our losartan + HCTZ group, heart rate decreased by 8.1 beats per minute from an initial value of 75 beats per minute, with no change in AIx, which further confirms the beneficial effect of losartan + HCTZ in neutralizing the negative effect of a reduction in heart rate.

In our study, a lower heart rate during treatment was associated with higher central systolic BP and AIx only in the bisoprolol + HCTZ group. Therefore, central systolic BP depended not only on heart rate during treatment, but also on the therapy prescribed. Losartan $+\mathrm{HCTZ}$ probably has some additional beneficial effect in decreasing central systolic BP despite a reduction in heart rate.

The effects of angiotensin receptor blockers on arterial stiffness and central BP have been investigated in other trials, eg, LIFE, MOSES (MOrbidity and mortality after Stroke - Eprosartan compared with nitrendipine for Secondary prevention), RENAAL (Reduction of Endpoints in NIDDM with the Angiotensin II antagonist Losartan), and IDNT (the Irbesartan Diabetic Nephropathy Trial), and their results could partly explain the positive effects of these agents in prevention of adverse cardiovascular outcomes. Logic suggests that any drug that decreases mean BP and has vasodilating properties (eg, the angiotensin receptor blockers) would improve vessel elasticity. However, experimental studies have shown that angiotensin receptor blockade is associated with remodeling of both small and large vessels as a result of specific mechanisms, eg, an antiinflammatory effect and impaired binding of $\alpha 5 \beta 1$-integrin with fibronectin, ${ }^{81}$ leading to decreased arterial stiffness regardless of effect on BP. Further, a low-calorie diet and low-dose valsartan was found to decrease central pulse BP but not mean BP in hypertensive rats. ${ }^{69}$ London et al and Agabiti-Rosei et al reported that angiotensin receptor blockade improved or even normalized the structure of resistance vessels and decreased the pulse wave reflection. ${ }^{33,39,82-84}$ Matsui et al showed that olmesartan + azelnidipine achieved a more pronounced reduction in PWVE than olmesartan + HCTZ, independent of mean BP reduction. ${ }^{60}$ 
The EXPLOR (Amlodipine-valsartan combination decreases central systolic blood pressure more effectively than the amlodipine-atenolol combination) trial showed that valsar$\tan +$ amlodipine was associated with more marked central systolic BP and AIx reduction than atenolol + amlodipine despite brachial BP reduction being similar for both groups. ${ }^{54}$ This difference persisted after standardization of heart rate. The authors attributed these differences mainly to changes in arterial tonus. $\beta$-blocker did not influence or increase the arterial tonus. In combination with calcium antagonist, bisoprolol did not provide enough vasodilation in comparison with the combination of angiotensin receptor blocker and calcium antagonist. Therefore, adding a calcium antagonist in our trial did not neutralize the insufficient $\beta$-blocker effect on central BP and additional cardiac load because of early summation of direct and reflected pulse waves.

\section{Study limitations}

This study had some limitations. First, patients received antihypertensive drugs before inclusion in the trial, so the arterial stiffness values recorded at baseline could have been affected not only by the disease itself but also by previous treatment, but this is unlikely to have influenced our results because there were no significant differences in arterial stiffness between the groups at baseline. Second, the trial was randomized but not blinded. However, our automatized data collection and processing using ambulatory blood pressure monitoring and a SphygmoCor device would have minimized the influence of human error. Third, some methodological limitations existed. We estimated pulse wave parameters after calibration based on brachial BP measurement, and the distance between pulse wave velocity measurement points was measured using a centimeter strip. However, the same clinicians performed the brachial BP measurements using the same technique in both groups. Fourth, our patients received statins as well as antihypertensive therapy, which could have influenced arterial stiffness and central systolic BP values in the whole study population, but it should be borne in mind that there were no significant differences between the groups in the proportions of patients on statin therapy. Further, ASCOT reported no significant differences in arterial stiffness and central systolic BP between groups of patients treated or not treated with atorvastatin..$^{85}$ Fifth, our trial had only a six-month follow-up period, which was probably too short to obtain significant data for changes in arterial stiffness in these patients. Sixth, a highly selective $\beta$-blocker without vasodilatory properties was used in our trial, and if other drugs such as nebivolol or carvedilol had been used, our findings may have been different. Finally, this was a single-center trial, for the simple reason that our center is the only site in the Ukraine that has a certified SphygmoCor device and specializes in the treatment of patients with severe hypertension, but this limitation would not have affected the comparative data obtained in the two treatment groups.

\section{Disclosure}

This work was funded by a grant from by KRKA Ukraine. GDR and YMS have received honoraria for educational lectures from KRKA Ukraine. SMK, OOT, and ASD report no conflicts of interest in this work.

\section{References}

1. Mancia G, De Backer G, Dominiczak A, et al. 2007 Guidelines for the management of arterial hypertension: The Task Force for the Management of Arterial Hypertension of the European Society of Hypertension (ESH) and of the European Society of Cardiology (ESC). J Hypertens. 2007;25:1105-1187.

2. Gil-Extremera B. ABPM study: efficacy of two fixed dose combinations, enalapril/nitrendipine versus. losartan/hydrochlorothiazide, in not controlled mild-moderate hypertensive patients. Am J Hypertens. 2003;16:A116.

3. Wilson TW, Lacourcière Y, Barnes CC. The antihypertensive efficacy of losartan and amlodipine assessed with office and ambulatory blood pressure monitoring. Canadian Cozaar Hyzaar Amlodipine Trial Study Group. CMAJ. 1998;159:469-476.

4. Dahlof B, Devereux RB, Kjeldsen SE, et al; LIFE Study Group. Cardiovascular morbidity and mortality in the Losartan Intervention for Endpoint reduction in hypertension study (LIFE): a randomized trial against atenolol. Lancet. 2002;359:995-1003.

5. Bangalore S, Wild D, Parkar S, Kukin M, Messerli FH. Beta-blockers for primary prevention of heart failure in patients with hypertension: insights from a meta-analysis. J Am Coll Cardiol. 2008;52: 1062-1072.

6. Panjrath G, Messerli F. Beta-blockers for primary prevention in hypertension: era bygone? Prog Cardiovasc Dis. 2006;49:76-87.

7. Cruickshank J. Beta-blockers continue to surprise us. Eur Heart J. 2000;21:354-364.

8. Mancia G. Prevention of risk factors: beta-blockade and hypertension. Eur Heart J. 2009;11:A3-A8.

9. Everly MJ, Heaton PC, Cluxton RJ Jr. Beta-blocker underuse in secondary prevention of myocardial infarction. Ann Pharmacother. 2004;38:286-293.

10. Lopez-Sendon J, Swedberg K, McMurray J, et al; Task Force On Beta-Blockers of the European Society of Cardiology. Expert consensus document on beta-adrenergic receptor blockers. Eur Heart J. 2004;25:1341-1362.

11. Rydén L, Standl E, Bartnik M, et al; Task Force on Diabetes and Cardiovascular Diseases of the European Society of Cardiology (ESC); European Association for the Study of Diabetes (EASD). Guidelines in diabetes, prediabetes and cardiovascular disease: full text. Eur Heart J. 2007;28:88-136.

12. Roman M, Devereux R, Kizer J, et al. High central pulse pressure is independently associated with adverse cardiovascular outcome the strong heart study. J Am Coll Cardiol. 2009;54:1730-1734.

13. Roman M, Devereux R, Kizer J, et al. Central pressure more strongly relates to vascular disease and outcome than does brachial pressure. The Strong Heart Study. Hypertension. 2007;50:197-203.

14. Williams B, Lacy P. Impact of heart rate on central aortic pressures and hemodynamic analysis from the CAFE (Conduit Artery Function Evaluation) study: CAFE-Heart Rate. J Am Coll Cardiol. 2009;54:705-713. 
15. Benetos A, Consoli S, Safavian A, Dubanchet A, Safar M. Efficacy, safety and effects on quality of life of bisoprolol/hydrochlorothiazide versus amlodipine in elderly patients with systolic hypertension. Am Heart J. 2000;140:11E.

16. Brion R, Carre F, Verdier J, et al. Comparative effects of bisoprolol and nitrendipine on exercise capacity in hypertensive patients with regular physical activity. J Cardiovasc Pharmacol. 2000;35:78-83.

17. Czuriga I, Riecansky I, Bodnar J, et al; NEBIS Investigators Group. Comparison of the new cardioselective beta-blocker nebivolol with bisoprolol in hypertension: the nebivolol, bisoprolol multicenter study (NEBIS). Cardiovasc Drugs Ther. 2003;17:257-263.

18. Wang B, Song W, Liu G. The effect long-term administration of a selective beta1 blocker bisoprolol on glucose metabolism in patients with essential hypertensive and type 2 diabetes mellitus. Zhonghua Nei Ke Za Zhi. 2005;44:503-505. Chinese.

19. Erdmann E, Lechat P, Verkenne P, Wiemann H. Results from post-hoc analyses of the CIBIS II trail: effect of bisoprolol in high-risk patient groups with chronic heart failure. Eur Heart J. 2001;3:469-479.

20. Ong K, Delerme S, Pannier B, et al. Aortic stiffness is reduced beyond blood pressure lowering by short-term and long-term antihypertensive treatment: a meta-analysis of individual data in 294 patients. J Hypertens. 2011;29:1034-1132.

21. Greenwald S. Pulse pressure and arterial elasticity. QJM. 2002;95: 107-112.

22. Karamanoglu M, O’Rourke MF, Avolio AP, Kelly RP. An analysis of the relationship between central aortic and peripheral upper limb pressure waves in man. Eur Heart J. 1993;14:160-167.

23. Safar M. Macro and Microcirculation in Hypertension. London, UK: Lippincott Williams \& Wilkins; 2005.

24. Wilkinson I, Franklin S, Hall I, Tyrrell S, Cockroft JR. Pressure amplification explains why pulse pressure is unrelated to risk in young subjects. Hypertension. 2001;38:1461-1466.

25. O’Brien E, Asmar R, Beilin L, et al; European Society of Hypertension Working Group on Blood Pressure Monitoring. European Society of Hypertension recommendations for conventional, ambulatory and home blood pressure measurement. J Hypertens. 2003;21: 821-848.

26. Sirenko Y. Arterial Hypertension. Kiev, Ukraine: Morion; 2002.

27. White W. Blood Pressure Monitoring in Cardiovascular Medicine and Therapeutics. Totowa, NJ: Humana Press; 2001.

28. Blacher J, Guerin AP, Pannier B, Marchais SJ, London GM. Arterial calcifications, arterial stiffness, and cardiovascular risk in end-stage renal disease. Hypertension. 2001;38:938-942.

29. Cameron JD, McGrath BP, Dart AM. Use of radial artery applanation tonometry and a generalized transfer function to determine aortic pressure augmentation in subjects with treated hypertension. J Am Coll Cardiol. 1998;32:1214-1220.

30. Cohn J. Is it the blood pressure or the blood vessel? Am J Hypertens. 2007;1:5-16.

31. Ichihara A, Hayashi M, Kaneshiro Y, et al. Low doses of losartan and trandolapril improve arterial stiffness in hemodialysis patients. Am J Kidney Dis. 2005;45:866-874.

32. Labat C, Lacolley P, Lajemi M, de Gasparo M, Safar ME, Benetos A. Effects of valsartan on mechanical properties of the carotid artery in spontaneously hypertensive rats under high-salt diet. Hypertension. 2001;38:439-443.

33. London GM, Asmar RG, O'Rourke MF, Safar ME. Mechanism(s) of selective systolic blood pressure reduction after a low-dose combination of perindopril/ indapamide in hypertensive subjects: comparison with atenolol. J Am Coll Cardiol. 2004;43:92-99.

34. Mackenzie I, McEniery C, Dhakam Z, et al. Comparison of the effects of antihypertensive agents on central blood pressure and arterial stiffness in isolated systolic hypertension. Hypertension. 2009;54: 409-413.

35. Safar ME, Blacher J, Pannier B, et al. Central pulse pressure and mortality in end-stage renal disease. Hypertension. 2002;39:735-738.
36. Kario K. Clinician's Manual on Early Morning Risk Management in Hypertension. London, UK: Science Press; 2004.

37. Wilkinson IB, MacCallum H, Flint L, Cockcroft JR, Newby DE, Webb DJ. The influence of heart rate on augmentation index and central arterial pressure in humans. $J$ Physiol. 2000;525:263-270.

38. Antikainen R, Jousilahti P, Tuomilehto J. Systolic blood pressure, isolated systolic hypertension and risk of coronary heart disease, strokes, cardiovascular disease and all-cause mortality in the middle-aged population. J Hypertens. 1998;16:577-583.

39. London G. Central blood pressure reduction: a key to organ protection. Medicographia. 2005;27:144-147.

40. Nichols W, O'Rourke M. McDonald's Blood Flow in Arteries: Theoretical, Experimental and Clinical Principles, 5th ed. London, UK: Hodder Arnold; 2005.

41. Nakamura M, Sato K, Nagano M. Estimation of aortic systolic blood pressure in community-based screening: the relationship between clinical characteristics and peripheral to central blood pressure differences. J Hum Hypertens. 2005;19:251-253.

42. Sharman JE, Stowasser M, Fassett RG, Marwick TH, Franklin SS. Central blood pressure measurement may improve risk stratification. J Hum Hypertens. 2008;22:838-844.

43. Dart AM, Gatzka CD, Kingwell BA, et al. Brachial blood pressure but not carotid arterial waveforms predict cardiovascular events in elderly female hypertensives. Hypertension. 2006;47:785-790.

44. Gómez-Marcos MA, Recio-Rodríguez JI, Rodríguez-Sánchez E, et al. Central blood pressure and pulse wave velocity: relationship to target organ damage and cardiovascular morbidity-mortality in diabetic patients or metabolic syndrome. An observational prospective study. LOD-DIABETES study protocol. BMC Public Health. 2010;10:143.

45. Laurent S, Boutouyrie P, Asmar R, et al. Aortic stiffness is an independent predictor of all-cause and cardiovascular mortality in hypertensive patients. Hypertension. 2001;37:1236-1241.

46. McEniery C, McDonnell Y, Munnery M, et al; Anglo-Cardiff Collaborative Trial Investigators. Variability and impact of cardiovascular risk factors the Anglo-Cardiff Collaborative Trial II. Hypertension. 2008;51:1476-1482.

47. McEniery C, Yasmin, Hall I, Qasem A, Wilkinson IB, Cockcroft JR; ACCT Investigators. Normal vascular aging: differential effects on wave reflection and aortic pulse wave velocity the AngloCardiff Collaborative Trial (ACCT). J Am Coll Cardiol. 2005;46: 1753-1760.

48. O'Rourke, Seward J. Central arterial pressure and arterial pressure pulse: new views entering the second century after Korotkov. Mayo Clin Proc. 2006;81:1057-1068.

49. Pini R, Cavallini M, Palmieri V, et al. Central but not brachial blood pressure predicts cardiovascular events in an unselected geriatric population. The ICARe Dicomano Study. J Am Coll Cardiol. 2008;51:2432-2439.

50. Williams B, Lacy PS, Thom SM. Differential impact of blood pressure lowering drugs on central aortic pressure and clinical outcomes principal results of the Conduit Artery Function Evaluation (CAFE) Study. Circulation. 2006;113:1213-1225.

51. Tsang TS, Verzosa GC, Barnes ME, et al. Central pulse pressure as a robust predictor of first atrial fibrillation: Study of Atrial Fibrillation In High Risk Elderly (SAFFIHRE). Circulation. 2008;118:1106.

52. Kullo I, Bielak L, Turner S, Sheedy P, Peyser P. Aortic pulse wave velocity is associated with the presence and quantity of coronary artery calcium: a community-based study. Hypertension. 2006;47:174-179.

53. Nelson M, Stepanek J, Cevette M, Covalciuc M, Hurst RT, Tajik AJ. Noninvasive measurement of central vascular pressures with arterial tonometry: clinical revival of the pulse pressure waveform? Mayo Clin Proc. 2010;85:460-472.

54. Boutouyrie P, Achouba A, Trunet P; EXPLOR Trialist Group. Amlodipine-valsartan combination decreases central systolic blood pressure more effectively than the amlodipine-atenolol combination: the EXPLOR study. Hypertension. 2010;55:1314-1322. 
55. Dart A, Cameron J, Gatzka C, et al. Similar effects of treatment on central and brachial blood pressures in older hypertensive subjects in the second Australian National Blood Pressure Trial. Hypertension. 2007;49:1242-1247.

56. Dhakam Z, McEniery C, Yasmin, Cockroft JR, Brown MJ, Wilkinson IB. Atenolol and eprosartan: differential effects on central blood pressure and aortic pulse wave velocity. Am J Hypertens. 2006;19:214-219.

57. Guido Grass G, Quarti-Trevano F, Mancia G. Cardioprotective effects of telmisartan in uncomplicated and complicated hypertension. J Renin Angiotensin Aldosterone Syst. 2008;9:66-74.

58. Mahmud A, Feely J. Antihypertensive drugs and arterial stiffness. Expert Rev Cardiovasc Ther. 2003;1:65-78.

59. Manisty C, Zambanini A, Parker K, et al; Anglo-Scandinavian Cardiac Outcome Trial Investigators. Differences in the magnitude of wave reflection account for differential effects of amlodipineversus atenolol-based regimens on central blood pressure an AngloScandinavian Cardiac Outcome Trial substudy. Hypertension. 2009;54: 724-730.

60. Matsui Y, Eguchi K, O'Rourke M, et al. Differential effects between a calcium channel blocker and a diuretic when used in combination with angiotensin II receptor blocker on central aortic pressure in hypertensive patients. Hypertension. 2009;54:716-723.

61. Morgan T, Lauri J, Bertram D, Anderson A. Effect of different antihypertensive drug classes on central aortic pressure. Am J Hypertens. 2004; 17:118-123.

62. Munir S, Guilcher A, Kamalesh T, et al. Peripheral augmentation index defines the relationship between central and peripheral pulse pressure. Hypertension. 2008;51:112-118.

63. Protogerou A, Blacher J, Stergiou GS, Achimastos A, Safar ME. Blood pressure response under chronic antihypertensive drug therapy: the role of aortic stiffness in the REASON (Preterax in Regression of Arterial Stiffness in a Controlled Double-Blind) study. J Am Coll Cardiol. 2009;53:445-451.

64. Rehman A, Ismail SB, Naing L, Roshan TM, Rahman AR. Reduction in arterial stiffness with angiotensin II antagonism and converting enzyme inhibition. A comparative study among male hypertensive subjects with a known genetic profile. Am J Hypertens. 2007;20:184-189.

65. Uehara G, Takeda H. Relative effects of telmisartan, candesartan and losartan on alleviating arterial stiffness in patients with hypertension complicated by diabetes mellitus: an evaluation using the cardio-ankle vascular index (CAVI). J Int Med Res. 2008;36: 1094-1102.

66. Hirata K, Vlachopoulos C, Adji A, O’Rourke MF. Benefits from angiotensin-converting enzyme inhibitor beyond blood pressure lowering: beyond blood pressure or beyond the brachial artery? J Hypertens. 2005;23:551-556.

67. Benetos A, Adamopoulos C, Bureau JM, et al. Determinants of accelerated progression of arterial stiffness in normotensive subjects and in treated hypertensive subjects over a 6-year period. Circulation. 2002;105:1202-1207.

68. Kingwell BA, Waddell TK, Medley TL, Cameron JD, Dart AM. Large artery stiffness predicts ischemic threshold in patients with coronary artery disease. J Am Coll Cardiol. 2002;40:773-779.
69. Mackenzie I, Wilkinson I, Cockcroft J. Assessment of arterial stiffness in clinical practice. QJM. 2002;95:67-74.

70. McVeigh GE, Bratteli CW, Morgan DJ, et al. Age-related abnormalities in arterial compliance identified by pressure pulse contour analysis: aging and arterial compliance. Hypertension. 1999;33:1392-1398.

71. Sutton-Tyrrell K, Mackey RH, Holubkov R, Vaitkevicius PV, Spurgeon HA, Lakatta EG. Measurement variation of aortic pulse wave velocity in the elderly. Am J Hypertens. 2001;14:463-468.

72. Vlachopoulos C, Alexopoulos N, Panagiotakos D, et al. Cigar smoking has an acute detrimental effect on arterial stiffness. Am J Hypertens. 2004; 17:299-303.

73. Blacher J, Asmar R, Djane S, London GM, Safar ME. Aortic pulse wave velocity as a marker of cardiovascular risk in hypertensive patients. Hypertension. 1999;33:1111-1117.

74. Blacher J, Pannier B, Guerin AP, Marchais SJ, Safar ME, London GM. Carotid arterial stiffness as a predictor of cardiovascular and allcause mortality in end-stage renal disease. Hypertension. 1998;32: 570-574.

75. Davies J, Struthers A. Pulse wave analysis and pulse wave velocity: a critical review of their strenghs and weaknesses. J Hypertens. 2003;21: $463-472$.

76. Safar M, Levy B, Struijker-Boudier H. Current perspectives on arterial stiffness and pulse pressure in hypertension and cardiovascular disease. Circulation. 2003;107:2864-2869.

77. Asmar R, Benetos A, Topouchian J, et al. Assessment of arterial distensibility by automatic pulse wave velocity measurement: validation and clinical application studies. Hypertension. 1995;26:485-490.

78. Vlachopoulos C, Alexopoulos N, Panagiotakos D, O'Rourke MF, Stefanadis C. Pressure altering agents affect central aortic pressure more than is apparent from upper limb measurements in hypertensive patients. The role of arterial wave reflections. Am J Hypertens. 2001;38:1456-1460.

79. Boutouyrie P, Tropeano AI, Asmar R, et al. Aortic stiffness is an independent predictor of primary coronary events in hypertensive patients: a longitudinal study. Hypertension. 2002;39:10-15.

80. Wilkinson I, Ian R, Hall I, et al. Pulse-wave analysis clinical evaluation of a noninvasive, widely applicable method for assessing endothelial function. Arterioscler Thromb Vasc Biol. 2002;22:147-152.

81. Kakou A, Bezie Y, Mercier N, et al. Selective reduction of central pulse pressure under angio-tensin blockage in SHR: role of the fibronectin$\alpha 5 \beta 1$ integrin complex. Am J Hypertens. 2009;22:711-717.

82. Agabiti-Rosei E, Heagerty AM, Rizzoni D. Effects of antihypertensive treatment on small artery remodeling. J Hypertens. 2009;27:1107-1114.

83. Agabiti-Rosei E, Porteri E, Rizzoni D. Arterial stiffness, hypertension, and rational use of nebivolol. Vasc Health Risk Manage. 2009;5:353-360.

84. Safar M, ProtogerouA, Blacher J. Central blood pressure under angiotensin and calcium channel blockade. Hypertension. 2009;54:704-706.

85. Williams B, Lacy P, Cruickshank J, et al; CAFE and ASCOT Investigators. Impact of statin therapy on central aortic pressures and hemodynamics principal results of the Conduit Artery Function Evaluation-Lipid-Lowering Arm (CAFE-LLA) study. Circulation. 2009;119:53-61.
Vascular Health and Risk Management

\section{Publish your work in this journal}

Vascular Health and Risk Management is an international, peerreviewed journal of therapeutics and risk management, focusing on concise rapid reporting of clinical studies on the processes involved in the maintenance of vascular health; the monitoring, prevention and treatment of vascular disease and its sequelae; and the involvement of

\section{Dovepress}

metabolic disorders, particularly diabetes. This journal is indexed on PubMed Central and MedLine. The manuscript management system is completely online and includes a very quick and fair peer-review system, which is all easy to use. Visit http://www.dovepress.com/ testimonials.php to read real quotes from published authors. 